\title{
revista de INDIAS
}




\title{
REDES DE PODER EN EL VIRREINATO DEL PERÚ, 1776-1824: LOS BURÓCRATAS*
}

\author{
POR \\ JOHN R. FISHER \\ Institute of Latin American Studies, University of Liverpool
}

El propósito claro de la Visita General del Virreinato del Perú encabezada por Antonio de Areche y Jorge de Escobedo en 1777-1785 era sanear la administración de la justicia y las finanzas con el objetivo politico de transferir el poder desde una supuestamente corrupta elite criolla a la gestión de peninsulares desinteresados. Este artículo analiza los resultados de esta política, a partir de un estudio biográfico de los elementos clave de la burocracia: los virreyes, los intendentes y los regentes de las audiencias de Lima y del Cusco, durante el periodo posterior a la conclusión de la Visita.

Palabras Claves: Virreinato del Perú, siglos XVIII-XIX, administración pública, finanzas, justicia, independencia.

\section{INTRODUCCION}

La historia del Virreinato del Perú durante los últimos cincuenta años del periodo colonial ha sido - $\mathrm{y}$ hasta cierto punto todavía es - uno de los principales focos de mi investigación durante casi cuatro décadas. Este interés se expresó en términos concretos por primera vez en 1970, cuando se publicó la edición inglesa del trabajo sobre la administración provincial bajo el régimen de las intendencias, introducidas en el Perú en 1784: el título del libro incluye la palabra 'sociedad', aunque hay que confesar que la preocupación por el estudio de la estructura social del Virreinato estuvo en función del interés por profundizar en una institución apenas conocida ${ }^{1}$. Siguió otro libro, ahora sobre la industria minera aproxi-

${ }^{*}$ Una versión preliminar de este artículo fue presentada en el XIV Congreso Internacional de AHILA (Castellón, 2005) con el apoyo de un Overseas Conference Grant, otorgado por The British Academy (ref. OCG-41495).

1 John R. FISHER, Government and Society in Colonial Peru: the Intendant System, London, 
madamente en el mismo periodo, que incluye un análisis de las intenciones y los resultados de los esfuerzos de la corona y sus representantes por modernizar y estimular la producción minera por medio de la implantación del Tribunal de Minería en 1786 y el envío de la misión mineralógica dirigida por Thaddeus von Nordenflicht ${ }^{2}$. En esta línea hay varios ensayos y artículos sobre otros aspectos del reformismo borbónico en el Perú, incluyendo la relación entre la rebelión de Túpac Amaru y el programa de la reforma imperial de Carlos III, durante el último cuarto del siglo XVIII, con atención al nuevo sistema de comercio popularmente conocido como 'el comercio libre'3.

Además, se añaden algunos ensayos sobre los fenómenos del regionalismo y del fidelismo en el Perú, antes y durante el período de las revoluciones hispanoamericanas de independencia; éstos incluyen algunas reflexiones sobre la aparente contradicción entre los problemas y agravios sufridos por grupos poderosos en el Virreinato a consecuencia del reformismo borbónico, y su extraordinaria lealtad a España durante la crisis general del Imperio en la segunda década del siglo XIX ${ }^{4}$. Finalmente, en un esfuerzo de resumir los resultados de éstos y otros trabajos sobre la historia del Perú durante los últimos 50 años del periodo virreinal, se publicó en 2000 el libro titulado El Perú Borbónico 1750-18245.

En una reseña publicada en American Historical Review de la versión revisada de esta obra, Paul Gootenberg observó que contiene mucha información útil sobre «trade, wars, and high politics...governance, defense and the church...economics, demography and finance....racial composition», junto con «acute observations about the shifting politics of interpreting Peru's reluctant independence... with a detailed archival account of royalist efforts to retain sovereignty $\rangle^{6}$. Pero añade que, «it does little to engage historians of the Andes working in subaltern, postcolonial, etnohistorical, local, transatlantic and cultural history». Este comentario, desde

Athlone Press, 1970; John R. Fisher, Gobierno y Sociedad en el Perú Colonial: el Régimen de las Intendencias, Lima, Pontificia Universidad Católica del Perú, 1981. En las citas siguientes la referencia es a la edición de 1981.

2 John R. Fisher, Silver Mines and Silver Miners in Colonial Peru, 1776-1824, Liverpool, Centre for Latin American Studies, University of Liverpool, 1976; John R. FisHeR, Minas y Mineros en el Perú Colonial 1776-1824, Lima, Instituto de Estudios Peruanos, 1977.

3 John R. FisheR, «La Rebelión de Túpac Amaru y el Programa de la Reforma Imperial de Carlos III», Anuario de Estudios Americanos, vol. XXXVIII, Sevilla, 1971, pp. 405-421; John R. FISHER, «El impacto del Comercio Libre en el Perú, 1778-1796», Revista de Indias, núms. 182-183, Madrid, 1988, pp.401-420.

4 John R. FISHER, «Royalism Regionalism and Rebellion in Colonial Peru, 1808-1815», Hispanic American Historical Review, vol. 59, 1979, pp. 232-257; John R. FiSHER, «The Royalist Regime in the Viceroyalty of Peru, 1820-1824», Journal of Latin American Studies, vol. 32, Cambridge, 2000, pp. 55-84.

5 John R. Fisher, El Perú Borbónico, 1756-1824, Lima, Instituto de Estudios Peruanos, 2000.

6 Paul Gootenberg, «Reviews...», American Historical Review, vol. 9, Washington, 2004, pp. 952-953. 
una óptica que no se adecúa a los objetivos de la obra, aumentó el interés por ella en los medios especializados.

La referencia a estos trabajos tiene un propósito definido, proporcionar el contexto para la comprensión de una observación que a primera vista podría llamar la atención: existe una relación directa entre la profundización del conocimiento del autor sobre el proceso de implantación de las reformas borbónicas en el Perú y su convicción de que este mismo proceso ha sido un mito, una invención historiográfica. $\mathrm{Y}$ en este caso, una invención impresionante y duradera, cuyo árbol genealógico fue sembrado hace más de doscientos años por el conde de Floridablanca en su elogio del reinado de Carlos III, escrito en 1788 para Carlos IV; sobre todo cuando insiste en defenderlo como un proceso coherente, decisivo, bien pensado y, sobre todo, exitoso ${ }^{7}$. ¿Cómo se puede explicar, en este sentido, la reforma de la administración interna, por ejemplo, cuando se toma conciencia del lapso de veinte años entre la presentación del informe de José de Gálvez de 1768, insistiendo en la urgente necesidad de reformar la administración decadente del Virreinato de Nueva España, y la eventual introducción del régimen de intendencias en 1786? Las mismas dudas surgen cuando se reflexiona acerca de la supresión en 1787-1788, de los puestos clave en la nueva estructura de las superintendencias de Real Hacienda en México, Lima y Buenos Aires, o de la decisión de abandonar los planes para la extensión del nuevo sistema de administración al Virreinato de Nuevo Granada ${ }^{8}$.

Aunque la muerte de Gálvez en 1787 no tuvo resultados tan regresivos en otro sector fundamental del reformismo - el de las reformas comerciales - también resulta relevante ponderar la contradicción entre la historiografía tradicional, con su insistencia en un proceso decisivo de cambio, y la incapacidad de la corona para extender el comercio libre a Venezuela y Nueva España sino hasta 1789, una década después de la promulgación del «Reglamento para el Comercio Libre», y casi cincuenta años después de la presentación ante la corte del Nuevo sistema de gobierno económico para la América de José Campillo9. El escrutinio de la aplicación de éstos y otros aspectos centrales del reformismo borbónico, no específicamente en el Perú sino en todo el imperio, podría llevarnos a la conclusión de que, si es todavía legítimo hablar de un programa, éste debe entenderse como una ópera (o, mejor dicho, una zarzuela) con muchos y largos intervalos entre un acto y otro. Con esta idea presente, pasemos a la consideración del reformismo borbónico en el Perú.

7 «Instrucción reservada», Antonio FERRER DEL RIO, Obras originales del Conde de Floridablanca y Escritos Referentes a su Persona, Madrid, Biblioteca de Autores Españoles, 1952, vol. LIX, pp. 213-272.

8 Una discusión exhaustiva acerca de esta cuestión se encuentra en Luis NAVARRO GARCIA, Intendencias en Indias, Sevilla, Escuela de Estudios Hispano-Americanos, 1959.

9 Véanse Geoffrey J. Walker, Spanish Politics and Imperial Trade, 1700-1798, London, Macmillan, 1979, y John R. FISHER, Commercial Relations between Spain and Spanish America in the Era of Free Trade, 1778-1796, Liverpool, Institute of Latin American Studies, 1985. 


\section{EL REFORMISMO BORBÓNICO EN EL PERÚ}

Es posible asumir que no existen muchos misterios acerca de las intenciones y la realización del programa de las reformas imperiales en el Virreinato del Perú, porque su aplicación coincidió con la Visita General de José Antonio de Areche y Jorge Escobedo entre 1777 y 1785, la primera fase de la cual ha sido relativamente bien descrita, aunque hace ya algún tiempo, por Vicente Palacio Atard, y la segunda en más detalle, en un trabajo reciente de Serena Fernández Alonso ${ }^{10}$.

También nos ayuda la larga tradición historiográfica española que presta más atención a intenciones y aplicaciones de proyectos de reforma que a sus consecuencias. La principal excepción temporal en la concentración del reformismo en este breve periodo (que continúa tal vez hasta 1787 y el regreso a España de Escobedo, quien se había quedado en el Perú como superintendente, después de concluir la Visita General en 1785) fue la reorganización militar, llevada a cabo durante la administración virreinal de Manuel de Amat (1761-1776). Este proceso ha sido estudiado por el historiador norteamericano Leon Campbell, quien enfatiza la incapacidad de las nuevas milicias para hacer frente a las tropas informales de Túpac Amaru, pero sin llegar a explicar (porque su estudio concluye en 1810) su extraordinario éxito al sofocar las rebeliones a favor de la independencia que empezaron en 1809-1810 en el Alto Perú, Chile y Quito y en el Virreinato en 1814, realizadas por insurgentes mejor armados y disciplinados ${ }^{11}$. A pesar de los posteriores esfuerzos valiosos de Juan Marchena de analizar las estructuras sociales del ejército peruano, todavía no se cuenta con una explicación clara y consistente de esta aparente contradicción ${ }^{12}$.

Tal vez ésta sea muy sencilla y también pueda extenderse a otros aspectos del reformismo, en el sentido de que sus consecuencias pueden entenderse solamente cuando se estudian en el contexto de los motivos y las necesidades de los peruanos, especialmente de los criollos. En este caso, muchos de ellos vieron la rebelión de Túpac Amaru, por lo menos al inicio, como otras protestas de la época, como un instrumento útil en su resistencia normalmente pasiva contra las reformas asociadas con la Visita General, mientras durante la segunda década del siglo XIX había una clara coincidencia entre sus ambiciones estrictamente peruanas y las necesidades de la corona.

10 Vicente PALACIO ATARD, Areche y Guirior: Observaciones sobre el Fracaso de una visita al Perú, Sevilla, Escuela de Estudios Hispano-Americanos, 1966; Serena FernÁndez Alonso, Presencia de Jaén en América: la Visita General de Jorge Escobedo al Virreinato del Perú en el Siglo XVIII (1782-1788), Jaén, Instituto de Estudios Gienenses, 1991.

11 Leon G. CAMPBELl, The Military and Society in Colonial Peru, 1750-1810, Philadelphia, The American Philosophical Society, 1978.

12 Juan MARCHENA FERnÁNDEZ, «The Social World of the Military in Peru and New Granada: the Colonial Oligarchies in Conflict, 1750-1810», John R. FisHER, Allan J. KuETHE y Anthony McFarlane (eds.), Reform and Insurrection in Bourbon New Granada and Peru, Baton Rouge, Louisiana State University Press, 1990, pp. 54-95. Véase también Juan MARCHENA FERNÁNDEZ, Ejércitos y Milicias en el Mundo Colonial Americano, Madrid, MAPFRE, 1992. 
A la vez que pensamos en las excepciones, resulta pertinente reflexionar brevemente sobre algunos vacíos importantes en la historiografía peruanista del periodo virreinal tardío, que incluyen un estudio moderno de la iglesia - específicamente del impacto del regalismo- a pesar de la existencia de algunos ensayos relevantes sobre la diócesis del Cusco del historiador australiano David P. Cahill ${ }^{13}$. También es curioso que aún no se ha escrito un estudio más exhaustivo sobre la Audiencia de Lima, cuya reforma fue una de las principales preocupaciones de Areche y Gálvez. El libro de Mark Burkholder sobre José Baquijano contiene algunas pinceladas fascinantes sobre el funcionamiento de esta institución después de la Visita General, aunque no pretende ser un estudio institucional; mientras, el trabajo anterior de Guillermo Lohmann Villena —recientemente fallecido-, sobre los ministros de la audiencia entre 1700 y 1821 ofrece un análisis muy general de su funcionamiento ${ }^{14}$. En el otro extremo, durante el último tercio del siglo XX, la mayoría de las investigaciones acometidas por una nueva generación de historiadores peruanos, especialmente de los formados intelectualmente en París, entre ellos el también desaparecido Alberto Flores Galindo, introducen interpretaciones muy dinámicas de la estructura social del Virreinato en este periodo, pero no las sitúan dentro de una consideración del reformismo borbónico: para ellos éste es un concepto demasiado imperialista, y la historia del imperialismo parece no interesarles mucho ${ }^{15}$. Sabemos algo sobre el Cabildo de Lima, pero muy poco sobre el Consulado: un trabajo del norteamericano John Melzer, algo confuso en su presentación, rescata alguna información útil sobre el comportamiento político de esta corporación, poderosa en vísperas de la independencia ${ }^{16}$.

El punto de partida para una consideración del reformismo en el Perú, especialmente con respecto a sus aspectos administrativos y económicos, como ya se ha establecido, debe ser el periodo que va de 1777 a 1785. Durante estos años los visitadores generales Areche y Escobedo lucharon contra los intereses egoístas de

13 Por ejemplo David P. CAHILl, «Curas and Social Conflict in the Doctrinas of Cuzco, 17801814», Journal of Latin American Studies, vol. 16, Cambridge, 1984, pp. 241-276. Una buena colección de los ensayos y artículos de este autor se encuentra en David P. CAHILL, From Rebellion to Independence in the Andes: Soundings from Southern Peru, 1750-1830, Amsterdam, Askant, 2002.

14 Mark A. Burkholder, Politics of a Colonial Career, José Baquijano and the Audiencia of Lima, Albuquerque, University of New Mexico Press, 1980; Guillermo LoHMANN VILLENA, Los Ministros de la Audiencia de Lima (1700-1821), Sevilla, Escuela de Estudios Hispano-Americanos, 1974.

15 Alberto Flores Galindo, La Ciudad Sumergida: Aristocracia y Plebe: Lima 1760-1830, Lima, Horizonte, 1990; Alberto Flores GALINDO, Buscando un Inca: Identidad y Utopía en los Andes, Lima, Horizonte, 1984.

16 John P. Moore, The Cabildo in Peru under the Bourbons, Durham, N. C., Duke University Press, 1966; John T.S. Melzer, Bastion of Commerce in the City of Kings: the Consulado de Comercio de Lima, 1593-1887, Lima, Consejo Nacional de Ciencia y Tecnología, 1991. Véase también Ana C. MAzzeo, El Comercio Libre en el Perú: Las estrategias de un comerciante criollo: José Antonio de Lavalle y Cortés, conde de Premio Real, 1775-1815, Lima, Pontificia Universidad Católica del Perú, 1995. 
los criollos, el conservadurismo virreinal, la mala administración judicial y financiera y el peso general de siglos de tradición para tratar de introducir el programa borbónico de reformas administrativas, judiciales, y financieras en el Virreinato.

Ambos eran conscientes de que su responsabilidad fundamental como agentes de la corona estaba en hacer la autoridad imperial más firme, en la convicción de que esta meta produciría rentas más altas para la Real Hacienda, así como la mejora del nivel de la administración judicial y de otros ramos. De la misma manera, vieron la concentración existente de poder en la capital del Virreinato como un impedimento para un control imperial efectivo debido a que los virreyes, en realidad, y tal vez inevitablemente - dada la enorme discrepancia entre sus poderes supuestos y reales - tendieron a ver su función como la preservación de los privilegios locales más que como la ejecución eficiente de la política del poder central. Manuel de Guirior, quien fue destituido como virrey en 1780 - porque cayeron sobre él sospechas de simpatizar con disturbios populares en contra de las reformas fiscales de Areche - estuvo motivado, insistió el visitador, por el deseo de retener la afección de criollos prominentes en Lima. El ministro de Indias anti-criollo, José de Gálvez, no tuvo ninguna duda en remover a Guirior, eliminando así este impedimento a su programa de reformas. Pero cuando Areche continuó comprometiéndose en disputas amargas con el nuevo virrey, Agustín de Jáuregui, el visitador también fue llamado a España en 1781, precisamente después del estallido de la rebelión de Túpac Amaru, para ser reemplazado por el más sutil Escobedo.

La rebelión indígena de 1780-1783, a pesar de que fue un choque profundo para la integridad militar, fiscal, y social del Perú, en realidad facilitó el proceso de acercar el virreinato al control central; lo que se logró intimidando a los criollos para frenar en el futuro cualquier resistencia abierta contra las innovaciones fiscales de la visita general. Al mismo tiempo proveyó a la corona con el motivo y la excusa necesarios para acelerar la erradicación del corrupto sistema de administración provincial que, se consideraba, había provocado el movimiento. El resultado fue la instalación del sistema de las intendencias en el Perú en 1784, con la creación de la superintendencia de Lima, que, como ya hemos mencionado, fue ocupada por Escobedo, y seis intendencias provinciales en las principales ciudades: Arequipa, Cusco, Huamanga, Huancavelica, Tarma, y Trujillo. Una octava intendencia peruana, la de Puno, fue creada en 1796, por la transferencia de esa provincia desde el Virreinato del Río de la Plata ${ }^{17}$.

\section{LOS BURÓCRATAS}

Esta sección tiene como fuente principal la bibliografía que aparece en la edición de El Perú Borbónico del año 2000 sobre los virreyes, visitadores, presiden-

17 FISHER, [1], pp. 43-63. 
tes-intendentes del Cusco, regentes de las audiencias de Lima y del Cusco, así como sobre los intendentes ${ }^{18}$. Durante el periodo que va de 1777 a 1782, el burócrata más poderoso en el Virreinato del Perú fue el visitador Areche. Este exfiscal de lo civil en la Audiencia de México, que habiendo colaborado estrechamente con José de Gálvez - cuya despectiva actitud para con los mexicanos compartió durante su visita general al Virreinato de la Nueva España entre 1766 y1771 - formalmente anunció en Lima, el 5 de septiembre de 1777, el inicio de su visita general a los «reinos del Perú y Chile, y de las provincias del Río de la Plata ${ }^{19}$. Gálvez - ministro de Indias desde febrero de 1776 - le apoyó incondicionalmente en una serie de disputas sostenidas con Guirior entre 1778 y 1779 , ordenando al virrey volver a España en enero de 1780, después de menos de cuatro años de mandato ${ }^{20}$. El sucesor de Areche como visitador, Escobedo, otro firme adhesor a los planes de Gálvez para erradicar la corrupción y elevar los ingresos de la Real Hacienda, llegó a Lima desde Potosí (donde, como subdelegado de la Visita, había reorganizado la Ceca) para asumir su nuevo cargo en marzo de $1782^{21}$. Escobedo permaneció en Lima durante casi seis años, inicialmente como visitador (hasta 1785) y, a partir de julio de 1784, con el triple cargo de intendente de la provincia de Lima, intendente del ejército y, más importante aún, superintendente subdelegado de la Real Hacienda ${ }^{22}$.

Aunque Gálvez apoyó a Escobedo durante una nueva serie de disputas con el virrey Jáuregui, tanto aquel como Escobedo eran más circunspectos ante el poderoso Teodoro de Croix, distinguido militar enviado a Lima desde Nueva España (donde había sido gobernador de Sonora y Sinaloa) y que asumió el puesto de virrey en Lima en abril de 1784, precisamente cuando Escobedo daba los toques finales al nuevo sistema de intendencias, claramente identificado, tanto simbólicamente como en la práctica, con una disminución en el prestigio del cargo de virrey ${ }^{23}$.

Austero e incorruptible (soltero y supuestamente célibe), Croix mantuvo una relación cordial aunque algo formal con Escobedo, no obstante su preocupación por insistir en la dignidad virreinal a expensas de la del superintendente. Los virreyes de la Nueva España y el Río de la Plata compartieron la hostilidad del virrey del Perú contra esta piedra angular del sistema de intendencias y no fue nin-

18 FISHER, [5], pp. 259-328.

19 Ibidem, pp. 280-282.

20 Ibidem, pp. 269-270.

21 Ibidem, pp. 283-284.

22 Gálvez ordenó el final de la Visita el 24 de enero de 1785, tras recibirse el detallado informe de Escobedo sobre la implementación del nuevo sistema de intendencias: Archivo General de Indias [En adelante AGI] Lima 646, Real Orden, 24 de enero de 1785; Lima 1117, Escobedo a Gálvez, 16 de julio de 1784. El original del informe formal de la Visita se encuentra en AGI, Lima 606, Escobedo a Gálvez, 20 de octubre de 1785.

23 FISHER [5], pp. 270-271. 
guna coincidencia que, a la muerte de Gálvez (el 17 de junio de 1787) le siguiera, casi de inmediato, la llamada de Escobedo a Madrid para ocupar el puesto de consejero de la Cámara del Consejo de Indias desde 1782 hasta su muerte en 1805 , y la transferencia de sus obligaciones como superintendente al virrey Croix $^{24}$. Esta decisión clave, tomada por el ministro de Guerra y Hacienda, Antonio Valdés, constituyó un gran cambio en el programa reformista de Carlos III (que moriría en 1788), porque señalaba claramente que los burócratas tradicionales - los virreyes - habían retomado el control de la administración en América. En el caso del Perú, por ejemplo, hay clara evidencia de que Croix (virrey hasta 1790) y su sucesor, Francisco Gil de Taboada y Lemos (1736-1809; virrey 17901796) resistieron los esfuerzos de varios intendentes de remover de sus puestos a varios subdelegados que se habían visto involucrados en el ya ilegal repartimiento de mercancías en las comunidades indígenas ${ }^{25}$. La explicación de esta postura es relativamente sencilla: por un lado, los virreyes compartían la opinión del Consulado de Lima de que la abolición del repartimiento había dañado la economía del Perú; por otro, querían hacer patente ante los intendentes que el mando permanecería en manos del virrey, una vez que éste recuperó el poder que le había sido arrebatado y entregado al superintendente.

Gil de Taboada, trasladado a Lima por su ex-colega en la Marina, Antonio Valdés, después de un breve periodo como virrey de Nueva Granada, también dió ciertas señales de regreso del nepotismo, nombrando a uno de sus sobrinos, Vicente Gil de Taboada, como intendente de la provincia de Trujillo en $1791^{26}$. Este último fue confirmado en este puesto en 1792 y lo ocupó durante casi treinta años, salvo por el disfrute de una licencia en España entre 1806 y 1810, durante la cual fue reemplazado por Felipe del Risco, un sobrino del virrey Gabriel de Avilés (1730-1810; virrey 1801-1806). La presencia de Vicente Gil de Taboada en España en 1809 salvó su puesto en Trujillo, en un momento en que la Junta Central y el Consejo de Regencia — respaldados algo a regañadientes por el virrey José Fernando de Abascal (1743-1821; virrey 1806-1816) - retiró de sus cargos a varios intendentes peninsulares que habían servido durante largo tiempo $\mathrm{y}$, en un esfuerzo por satisfacer la opinión criolla, los reemplazó con criollos ${ }^{27}$. A su regreso a Trujillo, Vicente Gil de Taboada parece haber gobernado con mano firme interfiriendo, por ejemplo, en las elecciones celebradas en 1813 para elegir a los diputados provinciales ante las Cortes $^{28}$.

24 AGI, Lima 1069, Antonio Valdés a Croix, 1 de agosto de 1787. En octubre de 1787 y mayo de 1788 se emitieron órdenes similares para México y Buenos Aires: FISHER [1], pp. 73-75.

25 FISHER [1], pp. 98-99.

26 FISHER [5], pp. 271-272.

27 Ibidem, [5], pp. 309-311. AGI, Lima 625, Abascal al Ministro de Estado, 21 de junio de 1811.

28 AGI, Lima 799, Representación de Miguel Tinoco, Juan Alejo Palacios y José María Núñez, 13 de septiembre de 1813 . 
Habiendo recibido del virrey Joaquín de la Pezuela (1761-1830; virrey 18161821) el permiso para retirarse debido a su mala salud, Vicente Gil de Taboada fue reemplazado en agosto de 1820 por el prominente limeño marqués de Torre Tagle, que tres meses después persuadió al Ayuntamiento de Trujillo para que se declarara en favor de la independencia ${ }^{29}$. Pezuela, el penúltimo virrey del Perú, como todos sus antecesores desde 1784 (Avilés y Abascal, ya mencionados, y Ambrosio O'Higgins, virrey desde 1796 hasta su muerte en 1801) era un militar destacado ${ }^{30}$. Su servicio en el Perú data de 1804, cuando llegó a Lima para reorganizar y comandar la artillería virreinal. Al igual que Abascal, Pezuela era profundamente hostil al régimen liberal que promulgó la Constitución de Cádiz en 1812, y concentró sus esfuerzos en la búsqueda de una solución puramente militar a la insurgencia en el Alto Perú, especialmente a partir de abril de 1813, cuando recibió de Abascal el mando supremo del ejército realista (principalmente conformado por peruanos) en esta región ${ }^{31}$. Ascendido a mediados de 1816, para suceder al ya viejo Abascal, Pezuela tuvo menos éxito en el cargo de virrey, que requería el manejo de problemas financieros y estratégicos cada vez más complejos.

Después de la evacuación al Callao en 1817 de los sobrevivientes del ejército realista que había perdido la batalla de Chacabuco, Pezuela nombró a su hijo político, Mariano Osorio, a la cabeza de una nueva expedición que sufriría una derrota humillante y decisiva a manos de José de San Martín, en la batalla de Maipú, el 5 de abril de 1818.32 Para los críticos de su mal manejo de la lucha contra la insurgencia - especialmente el grupo de oficiales peninsulares que habían llegado al Alto Perú desde España en 1816- el colmo de su desgracia fue la decisión de no atacar al ejército que San Martín llevó al Perú en septiembre de 1820. El resultado fue el golpe militar del 29 de enero de 1821, cuando 19 de los oficiales principales del ejército realista firmaron una petición demandando la renuncia de Pezuela en favor del teniente general José de la Serna (1770-1832), que serviría como virrey hasta su capitulación en Ayacucho, el 9 de diciembre de $1824^{33}$. Parece obvio que esta militarización definitiva del Virreinato durante el periodo que estamos estudiando, preparó el camino para las frecuentes intervenciones militares en la vida política de la nueva república, establecida teóricamente en 1821 y en la práctica no hasta 1824 .

Antes de entrar en unas consideraciones necesarias acerca de los intendentes, es importante mencionar brevemente algunos aspectos relativos a las audiencias.

29 Jaime E. Rodriguez, The Independence of Spanish America, Cambridge, Cambridge University Press, 1998, p. 217.

30 FISHER, [5], pp. 272-274.

31 Una narración detallada de sus campañas se encuentra en Félix DENEGRi LunA (ed.), $\mathrm{Me}$ moria Militar del General Pezuela (1813-1815), Lima, L.P. Villanueva, 1978.

32 Timothy E. AnNA, The Fall of the Royal Government In Peru, Lincoln, University of Nebraska Press, 1979, pp. 134-138.

33 FISHER [5], pp. 277-279. 
Como han demostrado muy claramente Burkholder y Chandler, entre otros, Gálvez insistió repetidamente en la necesidad de erradicar de estos tribunales a los ministros criollos - especialmente a los peruanos - reemplazándoles con peninsulares $^{34}$. Los resultados de esta política son muy claros: en 1777 la Audiencia de Lima contaba con seis ministros peruanos, uno criollo proveniente de otra región y sólo dos peninsulares. Después de la Visita, en 1785, había ya una clara mayoría de peninsulares - nueve - más cuatro peruanos y dos criollos provenientes de otras regiones. Veinte años más tarde, en 1805, había trece peninsulares y solamente dos americanos, uno de ellos peruano, en el Tribunal ${ }^{35}$. Los datos referentes a la audiencia más pequeña, la del Cusco, establecida en 1787, que empezó a funcionar formalmente en noviembre de 1788 y que contaba con cinco ministros, son aún más claros: Josef de la Portilla ( $i-1809$; regente 1787-1804), su primer regente, que había nacido en Córdoba y se había educado en Granada, volvería eventualmente a España para servir en el Consejo de Indias ${ }^{36}$. Su sucesor, Manuel Pardo Rivadeneira, (1759-1839; regente 1805-1821), originario de Lugo y educado en la Universidad de Santiago, actuó como un fuerte defensor de los intereses peninsulares en el Cusco, a pesar de los efectos desestabilizadores que la Constitución de 1812 tuvo en la ciudad ${ }^{37}$. Forzado a huir a Lima por la rebelión de Pumacahua de 1814-1815, Pardo escribió un detallado análisis de las causas de la rebelión, llegando a la conclusión de que sería extremadamente difícil erradicar la hostilidad que los criollos sentían con respecto a la autoridad peninsular ${ }^{38}$. Aunque casado (gracias a una licencia expedida por el virrey Avilés) con Marina Aliaga y Borda, heredera del poderoso criollo Marqués de Fuente Hermosa, Pardo regresó a España en 1821, desempeñando un cargo como miembro del Consejo de Hacienda. A pesar de que un arequipeño prominente, Pedro Mariano de Goyeneche (1772-1844) fue nombrado oidor en Cusco en 1807, el Tribunal continuaba funcionando como una institución peninsular, hasta su reemplazo, en febrero de 1825, por la Corte Superior de Justicia ${ }^{39}$.

El establecimiento del cargo de regente en las audiencias americanas en 1776 reflejaba una deliberada política real de limitar la influencia de los ministros criollos en estos tribunales. El primer regente de Lima, Melchor Jacot Ortíz Rojano (1732-1807; regente 1776-1782) era nativo de Málaga (al igual que Gálvez).

34 Mark A. Burkholder y D.S. Chandler, From Impotence to Authority: the Spanish Crown and the American Audiences, 1687-1808, Columbia, University of Missouri Press, 1977, pp. 83-135.

35 Ibidem, p. 153.

36 FISHER, [5], pp. 301-302.

37 Ibidem, pp. 302-303.

38 AGI, Cuzco 8, Pardo al Ministro de Gracia y Justicia, 13 de Julio de 1816, adjuntando la «Memoria Exacta de la Insurrección q'e ha experimentado la Prov’a y Capital del Cuzco».

39 La biografía de Goyeneche se encuentra en Mark, A. BuRKHOLDER y D.S. CHANDLER, Biographical Dictionary of Audiencia Ministers in the Americas, 1687-1821, Westport, Greenwood, 1982, pp. 151-152. 
Aunque fue un fiel funcionario que eventualmente ascendería a la Cámara del Consejo de Indias, su carrera pone en evidencia las insuperables dificultades que la corona debería enfrentar para impedir que sus representantes establecieran relaciones significativas con las elites locales, porque una vez fallecida su primera esposa, en 1787, Jacot recibió permiso real para contraer matrimonio, esta vez con María López de Maturana (de Huaura), quién, después de celebrada la ceremonia nupcial en Lima, donde Jacot fue representado por el prominente comerciante Isidoro de Abarca, conde de San Isidro, se le unió en Madrid ${ }^{40}$. Su sucesor en la regencia, Manuel Antonio Arredondo (1738-1822; regente 1787-1816) casó también con una peruana: en 1797 contrajo matrimonio con una acaudalada viuda, Juana Josefa de Herce y Dulce, de la cual heredó el título de Marqués de San Juan Nepomuceno, pero a su muerte la corona le negó repetidas veces el permiso para contraer matrimonio con otra rica mujer, Juana de Micheo Jiménez de Lobatón, viuda de José de Rezabal y Ugarte, antiguo oidor de Lima y regente de la audiencia de Chile. Aunque el heredero del regente, el brigadier Manuel Arredondo, volvió a España después de la independencia, muchos años más tarde su viuda, Ignacia Novoa, que permaneció en el Perú, recibió una compensación monetaria de parte del gobierno peruano por dos haciendas que le habían sido confiscadas a su marido por José de San Martín quien, a su vez, las había regalado a Bernardo O'Higgins en $1822^{41}$.

El último regente de Lima, Francisco Tomás de Ansotegui (1756-1822; regente 1816-1821) tuvo una larga carrera en América, siendo promovido desde Charcas para sustituir a Arredondo, cuando éste, ya anciano, se jubiló. Como la mayoría de los empleados civiles peninsulares en Lima, Ansotegui decidió no acompañar a La Serna cuando este último abandonó la ciudad de Lima en julio de 1821, tras conseguir de San Martín su pasaporte para regresar a España ${ }^{42}$.

La última y, en mi opinión, más importante piedra en las nuevas estructuras burocráticas construidas en el Perú por Gálvez y Escobedo, fue el sistema de intendencias, diseñado para reforzar el poder peninsular en el Perú, a través de la reducción de la autoridad del virrey, y la instalación en las capitales provinciales de funcionarios poderosos que estaban dedicados a apuntalar aún más la autoridad imperial. Seis de los siete intendentes nominados en 1784 fueron peninsulares, e igual lo fueron todos los demás intendentes nombrados hasta 1810 (veinte en total). Simbólicamente, aunque el criollo Nicolás Manrique de Lara fue desig-

40 Ibidem, pp. 101-102; FISHER [5], pp. 296-297.

41 FISHER [5], pp. 298-299.

42 Los detalles de la reunión celebrada en la casa de Ansotegui, el 21 de julio de 1821, donde los miembros de la audiencia decidieron si seguirían en sus puestos con los patriotas o regresarían a España, se encuentran en Guillermo DuRAND Flores, «Alta Cámara de Justicia», Quinto Congreso Internacional de Historia de América, 5 vols., Lima, Comisión Nacional del Sesquicentenario de la Independencia del Perú, 1972, vol. V, pp. 264-316. 
nado por Escobedo en el primer grupo como intendente de Huamanga, éste fue el único nombramiento no confirmado por la corona ${ }^{43}$.

Como ya hemos mencionado, los cambios políticos en España en 1808-1810 resultaron en algunas modificaciones de esta estructura, puramente peninsular. En Arequipa, por ejemplo, el veterano Bartolomé María de Salamanca, intendente desde 1796, fue reemplazado en 1815 por José Gabriel Moscoso, hijo de una prominente familia local, después de que el Consejo de Regencia hubiera considerado las quejas por mala administración formuladas por el Cabildo ${ }^{44}$. Cuando Moscoso fue ejecutado en enero de 1815 por las fuerzas insurgentes de Pumacahua, fue reemplazado por otro criollo, Juan Bautista de Lavalle y Zugasti, el quinto hijo del noble limeño conde de Premio Real ${ }^{45}$. Aunque en servicio activo con el ejército realista desde 1821, Lavalle no estuvo presente en Ayacucho porque estaba al mando de las reservas en Arequipa. Si bien fue invitado por la $\mathrm{Au}-$ diencia del Cusco a aceptar el cargo de presidente del tribunal inmediatamente después de la batalla, el prudente Lavalle decidió entregar el poder pacíficamente al primer prefecto de Arequipa, Francisco de Paula Otero en enero de 1825, y se dedicó a sus negocios privados.

La nueva política de reemplazar a peninsulares por criollos afectó también a otras provincias. En Huamanga, por ejemplo, los dos últimos intendentes fueron criollos: Manuel Quimper (1816-1819), que permaneció en su Lima nativa después de la independencia, y Francisco José de Recavarren, chileno, que fue sucedido interinamente por su yerno, Gabriel Herboso, cuando murió de una severa disentería en $1820^{46}$. El último intendente de Huancavelica, Juan Montenegro (1818-1820) también era arequipeño, aunque después de la capitulación de Ayacucho se trasladó a España. Lo mismo hizo el último intendente de Puno, Tadeo Gárate (1817-1824), nacido en La Paz, notorio en los círculos liberales por haber sido uno de los «persas», cuando representaba a Puno en las Cortes de Cádiz ${ }^{47}$.

Los dos últimos presidentes-intendentes del Cusco también fueron criollos: los arequipeños José Manuel de Goyeneche (1809-1814) —otro de los que partió a España después de Ayacucho- y Juan Pío de Tristán (1817-1824), el oficial realista de mayor graduación que logró escapar de la batalla ${ }^{48}$. Al igual que Lavalle, Tristán decidió que no tenía sentido mantener la resistencia realista, a pesar

43 FISHER [1], p. 8. Las biografías de los 32 intendentes de las provincias de Arequipa (5), Lima (3), Huamanga (5), Huancavelica (5), Puno (6), Tarma (4) y Trujillo (2) se encuentran en FISHER [5], pp. 305-328; las de los presidentes-intendentes del Cusco (7) se encuentran en Ibidem, pp. 287-295. Estas series incluyen solamente a los que recibieron títulos de la corona, excluyendo así a los interinos normalmente nominados por periodos cortos, por los virreyes.

44 FISHER [5], pp. 317-318, AGI, Lima 601, informe del Consejo de Indias, 19 de febrero de 1811.

45 FISHER [5], pp. 312-13.

46 Ibidem, pp. 319-321.

47 Ibidem, pp. 308-309.

48 Ibidem, pp. 293-295. 
de haber sido nombrado virrey por la Audiencia, y permitió que Agustín de Gamarra jurase como prefecto y comandante militar de Cusco a finales de diciembre de $1824^{49}$. Como era de esperarse, algunos de los intendentes criollos del Perú fueron más flexibles en su actitud hacia la formación de una república independiente que sus antecesores peninsulares.

\section{LOS RESULTADOS DE LAS REFORMAS}

El nuevo régimen de las intendencias tuvo éxito en su objetivo principal de mejorar la recaudación de ingresos para la Real Hacienda, aunque la curva ascendente fue menos impresionante después del estallido, en 1796, de una larga serie de guerras internacionales, que afectaron al comercio exterior y eventualmente al interior, así como a la recaudación de algunos impuestos.

En el área del gobierno local los intendentes no lograron resolver el problema de la mala administración en las zonas rurales, en parte por la obstrucción virreinal, pero principalmente porque una corona demasiado parsimoniosa no proveyó de los recursos para la creación de una estructura de servicio civil de oficiales locales pagados. Los subdelegados, que no recibían remuneración alguna, como los corregidores que existieron antes de ellos, fueron así reclutados entre las elites criollas locales, cuyos prejuicios acerca de la población indígena compartían. El resultado principal fue una continua resistencia indígena contra la presión fiscal, además de la intrusión de criollos y mestizos, no solamente en sus tierras comunales sino también en los cacicazgos ${ }^{50}$. De alguna manera, por supuesto, los disturbios rurales/indígenas tuvieron como resultado la magnificación del conservadurismo político de los criollos, aumentando así, por lo menos superficialmente, el poder de la corona.

Hay alguna evidencia de que en el terreno más amplio de la administración pública, en la parte que la Ordenanza de Intendentes identificaba como 'policía', los intendentes lograron un cierto éxito al estimular el desarrollo tanto cívico como provincial. Fueron elaborados algunos mapas, las provincias fueron visitadas, se construyeron puentes y caminos, se remitieron a España algunos ejemplares de plantas y minerales, además de que se hicieron intentos decisivos para estimular la participación de las elites locales en el mejoramiento de la calidad de los servicios municipales. No hay mucha evidencia, sin embargo, de que los esfuerzos de los intendentes en este ámbito tuvieran resultados significativos para la economía del Virreinato que, como antes, seguía siendo dominada por la industria minera.

49 Los detalles sobre el juramento de lealtad a Gamarra por parte del cabildo y otras dependencias se encuentran en Archivo Departamental del Cusco, Periódicos, libro 2A, f.11, Gamarra a José de Cáceres, 30 de diciembre de 1824.

50 Este tema se discute detalladamente en CAHILL [13]. 
El último cuarto del siglo XVIII y la primera década del siglo XIX vieron un importante salto hacia delante en la producción minera del Virreinato del Perú, a pesar de la transferencia del Alto Perú al nuevo Virreinato del Río de la Plata, una pérdida que privó al Perú de un $63 \%$ de su producción minera. Inicialmente, este hecho produjo un cierto pesimismo sobre las perspectivas económicas entre los representantes más conservadores de la oligarquía mercantil peruana y los miembros del Consulado. Esta interpretación negativa se profundizó en 1778, cuando la introducción del 'comercio libre' abolió el monopolio del comercio ultramarino, que hasta entonces disfrutaba el Callao y, aún más, con la abolición en 1780 del reparto de mercancías entre la población indígena del Virreinato. Todo esto ocurría en tanto que la Visita general elevaba los impuestos.

Sin hurgar demasiado en los detalles, se sabe que después de una baja inicial en la producción minera del Perú en 1777 — hasta sólo a dos millones de pesosse volvió a registrar un aumento de más del doble, hasta llegar a un promedio de cuatro millones y medio entre 1800 y 1811 debido, principalmente, al desarrollo de los centros mineros de Cerro de Pasco y Hualgayoc. Hubo, además, una interrelación directa entre esta expansión de la producción minera, la recuperación de la industria textil (especialmente la del centro y norte del Virreinato) y la prosperidad del comercio nacional e internacional ${ }^{51}$.

Uno de los debates actuales entre los especialistas en la historia económica de la América española en el siglo XVIII gira en torno al problema de si los aumentos en la producción minera - relativamente modestos en el caso del Perú, pero más espectaculares en el de Nueva España - tuvieron lugar espontáneamente, o sea, como resultado de decisiones deliberadas tomadas por los capitalistas locales, o bien fueron consecuencia de intentos premeditados promovidos por la corona para fomentar y proteger esta industria. En el caso peruano, la verdad del asunto está, probablemente, en una mezcla de ambos factores, porque es cierto que había una conexión directa entre el aumento de la producción y los esfuerzos de la corona de mejorar el abastecimiento de mercurio a través de grandes remesas extraídas de las minas de Almadén y embarcadas en Cádiz. Sin embargo, la adaptación por parte de Escobedo de las ordenanzas mineras mexicanas, y, como consecuencia, la organización de los mineros peruanos en un gremio encabezado por un tribunal de minería, tuvo poco impacto directo ${ }^{52}$.

En la esfera de la tecnología minera no se produjo progreso alguno en el Perú. Escobedo intentó fundar un colegio minero, como se proponía en el nuevo

51 Véanse Miriam SAlas DE COLOMA, «Los Obrajes de Huamanga en la Economía Centro-Sur Peruana a Fines del Siglo XVIII», Revista del Archivo General de la Nación, vol. 17, Lima, 1984, pp. 119-146, y Magdalena M. Chocano, Comercio en Cerro de Pasco a Fines de la Epoca Colonial, Lima, Seminario de Historia Rural Andina, Universidad Nacional Mayor de San Marcos, 1982.

52 Véase Miguel Molina Martínez, El Real Tribunal de Minería de Lima (1785-1821), Sevi1la, Diputación Provincial, 1986. 
Código de Minería, pero la falta de interés que mostró Madrid y la resistencia de los mineros a abandonar sus técnicas tradicionales impidieron la fundación de esa institución docente. En teoría, la misión minera de Nordenflicht brindaba un medio alternativo de mejorar la tecnología de esa industria, pero también esto fue un completo desastre. Su dificultad esencial radicó en que el nuevo procedimiento de refinación que Nordenflicht y su equipo de especialistas alemanes debían difundir en el Perú, resultó inadecuado en la práctica para el tipo de industria dispersa que allí se había creado. Si hubiera contado con una mayor cooperación por parte del Tribunal de Minería, y si los virreyes hubieran utilizado a sus colegas alemanes con más eficacia y buen sentido, quizá Nordenflicht habría podido contribuir a la mejora de la tecnología minera del Perú, pero la antipatía que se generó inmediatamente entre él y los representantes de la industria minera peruana fue empeorando cuanto más tiempo permanecía el sueco en el Virreinato. Su misión continuó oficialmente durante más de 20 años, pero sólo porque los ministros que se fueron sucediendo en Madrid olvidaron, literalmente, su presencia en el Perú, a medida que el programa de reforma imperial fue perdiendo ímpetu durante el reinado de Carlos IV.

¿Es posible, entonces, describir el aumento de la producción minera en el Perú tardío colonial en términos del triunfo del reformismo borbónico? La respuesta es clara: de ninguna manera. Por el contrario, los mineros peruanos rechazaron las reformas técnicas traídas al Virreinato por Nordenflicht y las decisiones de capitalistas y comerciantes de invertir su dinero en, por ejemplo, el desarrollo de Hualgayoc o la compra de máquinas de vapor inglesas para el drenaje de sus pozos en Cerro de Pasco, se tomaron por motivos locales y regionales, no imperiales. Los peruanos sabían mejor que la corona lo que querían y lo que no querían: afortunadamente para España, el primero de estos motivos incluía el mantenimiento de los lazos con la madre patria, por lo menos hasta que la victoria del ejército patriota en Ayacucho hizo inevitable la independencia ${ }^{53}$.

\section{CONCLUSIONES}

Los reformadores borbónicos — Gálvez, Escobedo y tal vez incluso el rey Carlos III- querían y creían que sus innovaciones podrían establecer en América el progreso económico, avances en la administración pública, así como estructuras judiciales y de gobierno menos corruptas. También creían que elevarían los

53 A pesar de la capitulación, como es bien sabido, el gobernador de Callao, Ramón Rodil, mantuvo la resistencia en las fortalezas del puerto hasta el 22 de enero de 1825 . Le acompañaron 3.800 refugiados civiles incluyendo, curiosamente, al marques de Torre Tagle, que murió ahí, junto con muchos otros miembros de la antigua elite criolla. Como ha observado un especialista: «no matter how mixed their motives might have been, these people were still voting against independence with their feet!», ANNA [32], p. 237. 
ingresos de la corona y harían más efectiva su autoridad. Obviamente, estas dos metas - la felicidad y prosperidad de los americanos, y la centralización de la autoridad metropolitana - eran incompatibles. Tanto en el Río de la Plata, como en Venezuela y Chile, la contradicción provocó luchas abiertas por la independencia a partir de 1810. En el Perú el resultado fue distinto, en parte porque los intendentes y los virreyes fueron capaces de mantener el equilibrio entre los intereses de los habitantes criollos del Virreinato y los de la corona; pero principalmente porque hubo una coincidencia fortuita entre los fines de ambos. En conclusión, las explicaciones del comportamiento especial de los peruanos durante el periodo de las revoluciones de independencia se encuentran, no en los motivos y la aplicación del reformismo borbónico, sino en las estructuras sociales, económicas y políticas existentes en el Virreinato. Además, los más perspicaces se dieron cuenta finalmente de que era posible mantener las mismas estructuras sociales en un sistema republicano. Por ejemplo, el único cambio en la administración provincial consistió en la nominación de prefectos para gobernar departamentos, idénticos a los que antes se encontraban en manos de intendentes. Sin embargo, los habitantes de algunas regiones descubrieron más tarde que, con la independencia, «quedó mermado el principio de autoridad de la burocracia, que hubiera podido fomentar mejores condiciones de vida en rincones apartados del territorio nacional, al margen de la correlación de fuerzas políticas dentro del gobierno central de Lima» ${ }^{54}$.

The clear aim of the general inspection of the Viceroyalty of Peru headed by Antonio de Areche and Jorge de Escobedo en 1777-1785 was to purify the administration of justice and finances by means of a policy of removing power from a supposedly corrupt creole elite and putting it in the hands of disinterested peninsular Spaniards. This article analyses the results of this policy by means of a biographical study of the key members of the bureaucracy - the viceroys, the intendants, and the regents of the audiencias of Lima and Cusco - during the period following the end of the inspection.

KeY wORDS: Viceroyalty of Peru, XVIII-XIX centuries, Public Administration, Finances, Justice, Independence.

Fecha de recepción: 10 de Septiembre de 2005.

Fecha de aceptación: 14 de Diciembre de 2005.

54 Teodoro Hampe Martínez y José F. Gálvez Montero, «De la Intendencia al Departamento (1810-1830): Los cambios en la administración pública regional del Perú», Marco BELLINGERI (ed.), Dinámicas del Antiguo Régimen y Orden Constitucional: Representación, Justicia y Administración en Iberoamérica. Siglos XVIII-XIX, Torino, Otto Editore, 2000, p. 360. 